\title{
Micro-Propagation of White-top Aster, Sericocarpus rigidus, a Threatened Species from the Garry Oak Ecosystem in British Columbia
}

\author{
BRENDA Frey, Chaim KeMPLER, and DAVID L. Ehret ${ }^{1}$ \\ Pacific Agri-Food Research Centre, Agriculture and Agri-Food Canada, PO Box 1000, Agassiz, British Columbia V0M 1A0 \\ Canada \\ ${ }^{1}$ Author to whom correspondence should be addressed; e-mail: ehretd@agr.gc.ca
}

Frey, Brenda, Chaim Kempler, and David L. Ehret. 2007. Micro-propagation of White-top Aster, Sericocarpus rigidus, a threatened species from the Garry Oak Ecosystem in British Columbia. Canadian Field-Naturalist 121(1): 40-45.

\begin{abstract}
A study was undertaken to examine the feasibility of using micro-propagation techniques to regenerate White-top Aster (Sericocarpus rigidus), a threatened species native to the Garry Oak ecosystem in coastal British Columbia. Shoot multiplication from explants was compared in three different basal media formulations. The effects of varying IAA (indole-3-acetic acid) and kinetin on shoot production were also investigated using one of the three basal media. Shoot production was most successful on modified MS (Murashige and Skoog) media containing various concentrations of BAP (benzylaminopurine) and $\mathrm{GA}_{3}$ (gibberellic acid), followed by media containing IAA and kinetin at concentrations of $2 \mathrm{mg} \mathrm{l}^{-1}$. Root formation occurred readily on modified MS media with IAA and reduced macronutrient and micronutrient concentrations. The study showed that $S$. rigidus can be successfully propagated using in vitro shoot multiplication.
\end{abstract}

Key Words: Sericocarpus rigidus, Aster curtus, White-top Aster, micro-propagation, Garry Oak ecosystem, British Columbia.

The Garry Oak ecosystem has a geographic distribution that spans the west coast of North America, from southwestern British Columbia to southern California. In recent years, the survival of this ecosystem in Canada has been threatened by fire suppression and by residential, industrial and agricultural development. These activities have resulted in loss of species habitat, habitat degradation and the spread of invasive exotic species (Garry Oak Ecosystem Recovery Team 2002*). The Garry Oak ecosystem contains more plant species than any other terrestrial ecosystem in coastal British Columbia, and many plants that live in the ecosystem do not occur elsewhere in Canada. It is now estimated that less than 5\% of all Garry Oak sites remain in their natural state (Garry Oak Ecosystem Recovery Team 2002*).

The White-top Aster, Sericocarpus rigidus (formerly Aster curtus), is an herbaceous perennial species of Asteraceae native to low elevation grasslands in the Pacific Northwest in the United States and the associated Garry Oak ecosystem on Vancouver Island, British Columbia (Clampitt 1987). Due to the serious loss of habitat, the Committee on the Status of Endangered Wildlife in Canada (COSEWIC) designated White-top Aster as a threatened species in 1996, and the species is now protected under the Species At Risk Act (SARA) (Environment Canada 2006*). Sericocarpus rigidus produces underground rhizomes, and as a result, occurs in patches which can vary tremendously in size. Shoots emerge from rhizomes in April, flower in July and August, then die back in the autumn. Seedlings are rarely, if ever, observed, making rhizomes the major form of propagation (Douglas and Illingworth 1997). Even though $S$. rigidus produces an abundance of seeds, via- bility is low and often uneven. In pollination studies, Clampitt (1987) found that excluding pollinators by bagging ramets significantly reduced the percentage of viable seeds (measured with tetrazolium chloride) from $20 \%$ in the unbagged treatment to $5 \%$ in the bagged. Bigger (1999) found that exposed and handpollinated flowers generally had the same number of viable seed (as tested with tetrazolium chloride), but differences in seed viability between hand-pollinated and exposed plants varied greatly among sites, possibly due to pollinator limitations in some patches. Patch size was also found to influence the degree of predation by insects. Overall, seed viability varied from 0 to $83 \%$. In a field comparison of open pollinated, between patch pollinated, within patch pollinated and pollination excluded treatments, Giblin (1997) found that open and between patch pollination treatments produced significantly more filled seed (39\% and 35\%, respectively) than within patch and pollination exclusion treatments (18\% and 9\%, respectively). In terms of conditions required for germination, Clampitt (1987) showed that stratification and exposure to light increased germination. Ehret et al. (2004) have shown that the seeds required an 8-12 week period of stratification for germination and seedlings are slow to establish. Even so, Giblin and Hamilton (1999) suggest that the reproductive biology of the species does not contribute to its rarity.

Sericocarpus rigidus was one of three species "at risk" plants studied at the Pacific Agri-Food Research Centre (PARC) with the objective of developing propagation methods that would allow for the generation of plant material that could be reintroduced into protected Garry Oak ecosystems, parks and ecological 
reserves or made available to native plant nurseries. Because of the difficulties associated with seed germination, micro-propagation was studied with the objective of developing a method that could rapidly and reliably produce plantlets.

\section{Materials and Methods \\ Plant Material}

Seeds were collected from two patches of S. rigidus growing at an elevation of $220 \mathrm{~m}$ on Mt. Tzuhalem $\left(48^{\circ} 47^{\prime} \mathrm{N}, 123^{\circ} 38^{\prime} \mathrm{W}\right)$ on Vancouver Island in September 2001 and from another patch at the same location in September 2002. The collection sites were 100 to $300 \mathrm{~m}$ apart. Given the close proximity, all plants may have been derived from the same clone. Collected seed count varied from 50 to 200 per plant. Seeds from 2001 were dried and stored at room temperature in the dark for one year. In September 2002, all seeds were placed in the dark in a cooler at $4{ }^{\circ} \mathrm{C}$. In October 2002, 15 to 30 seeds from each patch were placed on damp filter paper in petri dishes and incubated in a growth chamber maintained at $20^{\circ} \mathrm{C}$ and $14 / 10 \mathrm{~h}$ light/dark. After three weeks, only four seeds had germinated and all were collected from the same patch in 2001. These were potted in $10 \mathrm{~cm}$ pots containing Sunshine Mix 4, (Sun Gro Horticulture Inc., Vancouver, British Columbia) and were over-wintered in a greenhouse. In May 2003 the seedlings were hardened off in a cold frame for four weeks before being transplanted into a silt loam soil in irrigated raised beds at PARC. After one season of growth and flowering, seeds were collected from those plants in October 2003, and after air drying, were stored in a cooler at $4^{\circ} \mathrm{C}$ for 3 months. Surface sterilization of 10 seeds was conducted by suspending the seeds in a 5\% solution of PPM (Plant Preservative Mixture) (Plant Cell Technology Inc., Washington D.C., USA) and deionized water (v/v) in a beaker on a shaker for $24 \mathrm{~h}$. Seeds were aseptically transferred to a petri dish containing a $1.5 \%$ solution of sterile Bacto agar in deionized water (w/v). The petri dish was sealed with parafilm and placed in a plastic bag in a refrigerator at $3^{\circ} \mathrm{C}$ in the dark.

After nine weeks at $3^{\circ} \mathrm{C}$, one seed germinated. This was the only seed that germinated during the next five months. The seedling was removed from the petri dish under sterile conditions and placed in a $350 \mathrm{ml}$ jar containing half-strength MS (Murashige and Skoog 1962) media containing $1.0 \mathrm{mg} \mathrm{L}^{-1} \mathrm{IAA}$ and $0.1 \mathrm{mg} \mathrm{L}^{-1}$ kinetin. The jar was placed in a growth room maintained at $22-25^{\circ} \mathrm{C}$ with a $16 / 8 \mathrm{~h}$ light/dark cycle using fluorescent light with a PPFD (photosynthetic photon flux density) of $\sim 50 \mu \mathrm{E} \mathrm{m}^{-2} \mathrm{~s}^{-1}$. After five weeks, the fully developed, healthy seedling was transferred to a modified MS medium containing half the concentration of ammonium nitrate $(825 \mathrm{mg} \bullet \mathrm{L}), 2.0 \mathrm{mg} \bullet \mathrm{L}^{-1} \mathrm{IAA}$ and $2.0 \mathrm{mg} \mathrm{l}^{-1}$ kinetin. After four weeks on this medium, shoot and roots were excised and cultured on fresh media. Cultures were maintained by bimonthly trans- fer to fresh media until enough shoots were generated to conduct shoot multiplication and rooting experiments. The excised root tissue failed to grow after being removed from the shoot and was discarded.

\section{Shoot Induction}

A replicated shoot multiplication experiment was initiated to determine the effects of various concentrations of IAA plus kinetin or BAP plus $\mathrm{GA}_{3}$ on the growth of explant shoots produced on modified MS media. The experimental design was a randomized complete block design consisting of seven media treatments with six replicate jars, each containing five explants. The experiment included three modified MS basal medium (BM) formulations with each formulation containing a different concentration of macronutrients, micronutrients and organic additives (Table 1). BM1 was a formulation used in earlier micropropagation media development using the cultivated violet species, Viola praemorsa (Ehret et al. 2004). BM2 and BM3 were modified MS media used routinely in the PARC strawberry and raspberry breeding programs for shoot proliferation. The ammonium nitrate concentration of BM1 was half that of the other media because higher rates of ammonium nitrate have been found to be toxic to cultures of some plant species because the uptake of ammonium ions can acidify the medium and increase the frequency of vitrification (Slater et al. 2003). BM1 was the basal media used in media treatments 1 through 5 and it was supplemented with five combinations of IAA and kinetin as follows: $0.5 \mathrm{mg} \cdot \mathrm{L}^{-1}$ $\mathrm{IAA}+1.0 \mathrm{mg} \cdot \mathrm{L}^{-1}$ kinetin $(\mathrm{M} 1), 0.5 \mathrm{mg} \cdot \mathrm{L}^{-1} \mathrm{IAA}+$ $2.0 \mathrm{mg} \bullet \mathrm{L}^{-1}$ kinetin $(\mathrm{M} 2), 2.0 \mathrm{mg} \bullet \mathrm{L}^{-1} \mathrm{IAA}+1.0 \mathrm{mg} \bullet \mathrm{L}^{-1}$ kinetin (M3), $2.0 \mathrm{mg} \cdot \mathrm{L}^{-1} \mathrm{IAA}+2.0 \mathrm{mg} \cdot \mathrm{L}^{-1}$ kinetin $(\mathrm{M} 4)$ and $3.0 \mathrm{mg} \bullet \mathrm{L}^{-1} \mathrm{IAA}+2.0 \mathrm{mg} \mathrm{l}^{-1}$ kinetin (M5). M4 was the initial shoot multiplication media used to generate plant material for the experiment. BM2 was the basal media used in treatment 6 (M6) and it was supplemented with $2.5 \mathrm{mg} \bullet \mathrm{L}^{1} \mathrm{BAP}$ and $0.01 \mathrm{mg} \bullet \mathrm{L}^{-1} \mathrm{GA}_{3}$. BM3 was the media used in treatment 7 (M7) and it was supplemented with $1.0 \mathrm{mg} \bullet \mathrm{L}^{-1}$ BAP and $0.01 \mathrm{mg} \bullet \mathrm{L}^{-1}$ $\mathrm{GA}_{3}$. The ferrous sulphate and Fe-EDTA supplied in BM1 and BM2 was replaced by Sequestrene 138 (Becker Underwood Inc., Ames, Iowa, USA) in BM3.

The $\mathrm{pH}$ of all media treatments was adjusted to 5.65.7 and the media were then dispensed into $350 \mathrm{~mL}$ jars which were covered with cellophane and autoclaved. Explants which had a mean weight of $0.164 \mathrm{~g} \pm 0.008$ (SE), were aseptically transferred into treatment jars which were incubated in a growth room maintained at $22-25^{\circ} \mathrm{C}$ with a $16 / 8 \mathrm{~h}$ light/dark cycle using fluorescent light with a PPFD of $\sim 50 \mu \mathrm{E} \mathrm{m}^{-2} \mathrm{~s}^{-1}$ for four weeks. After four weeks, the number of explants that produced shoots and roots, the number of shoots produced per explant, and shoot and explant fresh weights were recorded.

\section{Root Induction}

A separate rooting experiment was conducted using BM4 (Table 1) which is used in the PARC berry breed- 
TABLE 1. Four modified Murashige and Skoog (MS) basal media (BM) formulations used for S. rigidus culture. Rates are expressed in $\mathrm{mg}^{-1} \mathrm{l}^{-1}$ with the exception of Plant Preservation Mixture, which is expressed in $\mathrm{ml} \mathrm{l}^{-1}$.

\begin{tabular}{|c|c|c|c|c|}
\hline & & Iction Med & & \\
\hline & & Shoot & & Root \\
\hline & BM1 & BM2 & BM3 & BM4 \\
\hline Macronutrients & & & & \\
\hline Ammonium nitrate & 825 & 1650 & 1237 & 464 \\
\hline Calcium chloride (anhydrous) & 332 & 332 & 332 & 332 \\
\hline Magnesium sulphate $\left(\mathrm{MgSO}_{4} \cdot 7 \mathrm{H}_{2} \mathrm{O}\right)$ & 370 & 370 & 370 & 370 \\
\hline Potassium phosphate & 170 & 170 & 170 & 64 \\
\hline Potassium nitrate & 1900 & 1900 & 1425 & 534 \\
\hline Micronutrients & & & & \\
\hline Boric acid & 6.2 & 6.2 & 6.2 & 3.1 \\
\hline Cobalt chloride & 0.025 & 0.025 & 0.025 & 0.013 \\
\hline Cupric sulphate & 0.025 & 0.025 & 0.025 & 0.013 \\
\hline Ferrous sulphate & 27.8 & 27.8 & - & - \\
\hline Manganese sulphate & 22.3 & 22.3 & 22.3 & 11.2 \\
\hline Potassium iodine & 0.83 & 0.83 & 0.83 & 0.42 \\
\hline Sodium molybdate & 0.25 & 0.25 & 0.25 & 0.13 \\
\hline Zinc sulphate & 8.6 & 8.6 & 8.6 & 4.3 \\
\hline $\mathrm{Na}_{2}$ EDTA & 37.2 & 37.2 & - & - \\
\hline Sequestrene 138 & - & - & 200 & 100 \\
\hline Sodium phosphate $\left(\mathrm{NaH}_{2} \mathrm{PO}_{4} \cdot \mathrm{H}_{2} \mathrm{O}\right)$ & - & 170 & 170 & 85 \\
\hline Organic Additives & & & & \\
\hline Sucrose & 20 & 30 & 30 & 30 \\
\hline myo-inositol & 1000 & 100 & 100 & 100 \\
\hline Nicotinic acid & 0.5 & - & - & - \\
\hline Pyridoxine $\cdot H C L$ & 0.5 & - & - & - \\
\hline Thiamine & 0.1 & 0.8 & 0.8 & 0.4 \\
\hline Glycine & 20 & - & - & - \\
\hline Adenine & - & 80 & 80 & - \\
\hline Plant Preservation Mixture & 2 & 2 & 2 & 2 \\
\hline Gerlite guar gum & 2 & 2 & 2 & 2 \\
\hline
\end{tabular}

ing program for root development. Fifteen shoot samples initiated on M4 were placed on the rooting medium containing $1.0 \mathrm{mg} \cdot \mathrm{L}^{-1}$ IAA. After four weeks, rooted plants were transferred to Sunshine Mix 4 potting mix and moved to a greenhouse where they were acclimatized.

\section{Statistical Analysis}

Data were analysed using the general linear model procedure in SAS (SAS Institute, Cary, North Carolina, USA), for one-way analysis of variance (ANOVA). All independent factors were fixed. Where ANOVA results were significant, treatment means were separated by Duncan's multiple range tests. Data expressed in percentages were transformed by arcsin transformations before statistical analysis.

\section{Results and Discussion}

In general, explants grew rapidly in culture, with extensive shoot multiplication (Figure $1 \mathrm{a}, \mathrm{b}$ ). After four weeks of culture, explant survival ranged from 83.3 to 100 percent with no significant survival differences among media treatments (Table 2). The percentage of surviving explants that produced shoots ranged from 61 to $100 \%$. Just over $60 \%$ of M1 and M3 explants produced shoots compared to $90-100 \%$ of ex- plants cultured on M4-M7. In addition, explants cultured on M1, M2 or M3 produced roots while being cultured on shoot multiplication media (data not presented). M1 and M3 which had the lowest concentrations of kinetin produced the greatest number of roots, 13 and $20 \%$ respectively. These results suggest that aster media should contain kinetin at minimal rates of $2.0 \mathrm{mg} \cdot \mathrm{L}^{-1}$ to avoid root initiation during the shoot multiplication stage. This supports previous recommendations that kinetin be added to a medium for cell division, shoot multiplication and axillary bud proliferation while IAA should be added to promote cell enlargement, root initiation and adventitious bud formation (Kyte and Klein 1999).

Mean explant plus shoot weights ranged from 0.241 to 0.855 grams. No statistically significant differences were observed among BM1 treatments. M6 produced a significantly greater biomass than all other media, followed by M7 which had a significantly greater biomass than M1 to M3 (Table 2, Figure 1c). Explants and shoots cultured on M6 appeared slightly chlorotic compared to those cultured on M7 which were the darkest green of all treatments (data not presented). Explants cultured on M2 and M3 were the least vigorous; explant and shoot leaves appeared mottled and there 

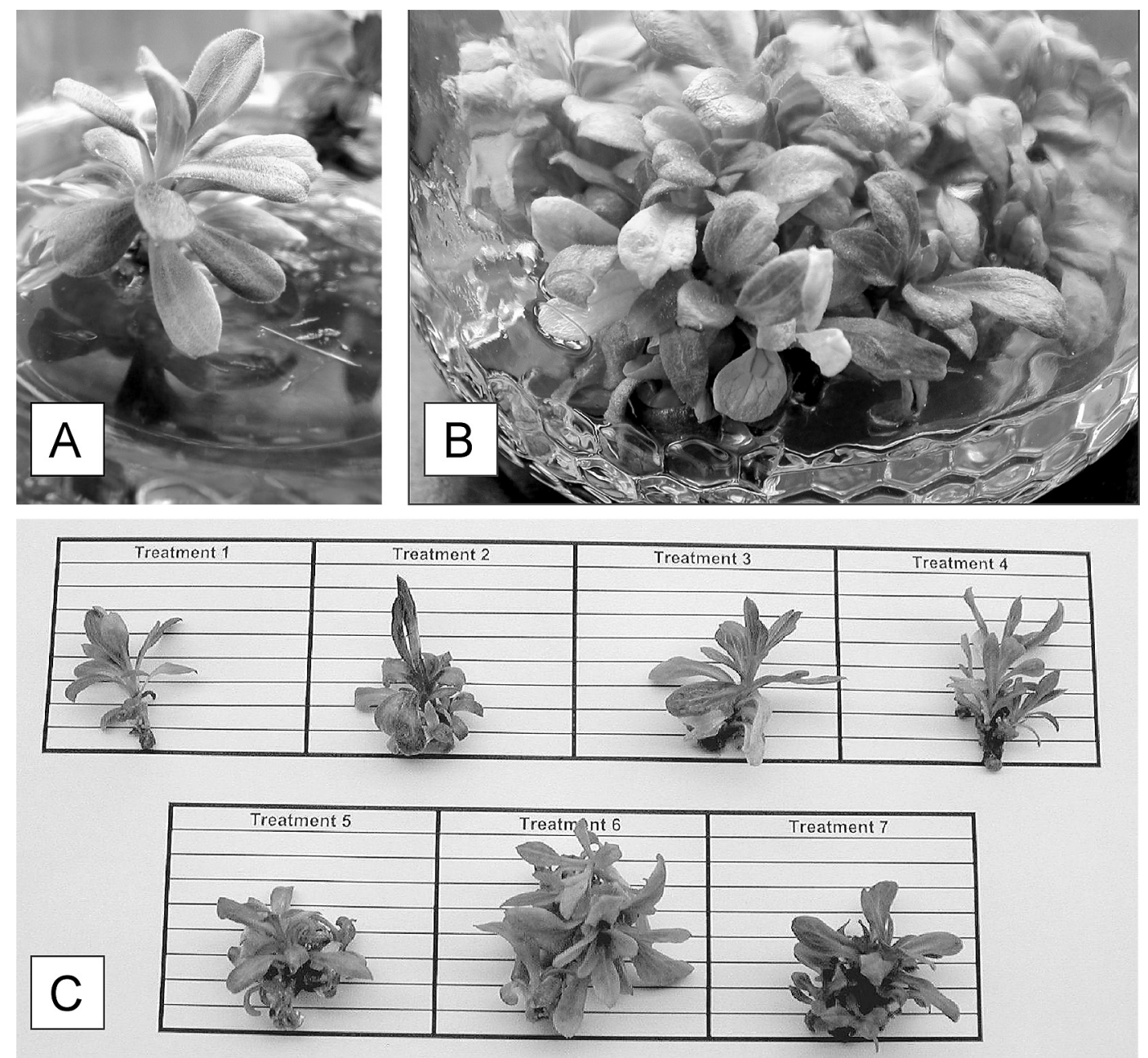

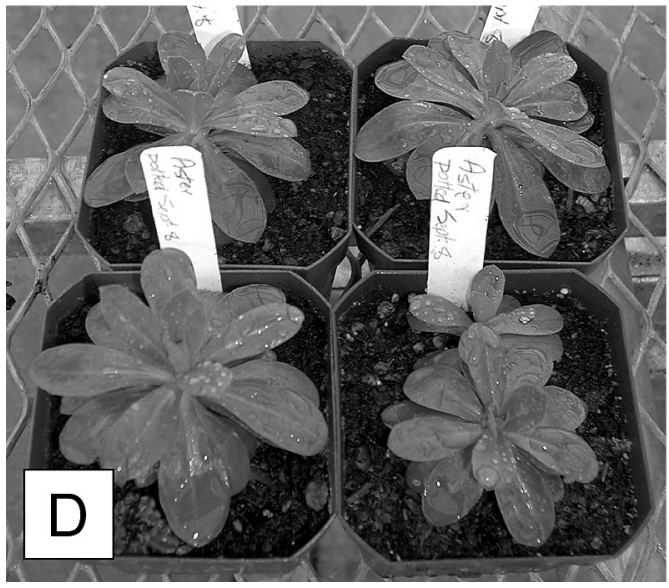

were several dead leaves at the base of the explants.

The number of shoots per surviving explant ranged from 1.72 to 6.19 shoots per explant (Table 2). Within the BM1 treatments, M2 and M3 produced significant-
FIGURE 1. A. Seriocarpus rigidus explant on culture media after two weeks in culture. B. Explants and developed shoots on media after 4 weeks. C. Representative samples of explants and shoots cultured on seven media treatments after 4 weeks of culture. Treatment labels 1 through 7 represent treatments M1 through M7, respectively. D. Four-month-old rooted aster plants in the greenhouse.

ly fewer shoots than M4. Treatments M6 and M7, both of which contained BAP and $\mathrm{GA}_{3}$ and which were on $\mathrm{BM} 2$ and $\mathrm{BM} 3$, respectively, produced a greater number of shoots per explant than most BM1 treatments containing combinations of IAA and kinetin.

The mean weight of individual shoots cultured on the different media ranged from 0.037 to 0.097 grams per shoot. Few consistent differences were observed among the five BM1 treatments. Compared to those treatments, M6 (on BM2 with BAP and $\mathrm{GA}_{3}$ ) produced shoots with the greatest weight. Despite some differences among BM1 treatments, the results show 
that the ratio and the concentration of IAA and kinetin in BM1 did not have a consistent effect on overall shoot multiplication. Shoots were small and difficult to handle after four weeks of culture. Extending the culture time from four to five weeks would likely have increased shoots to a size that would have made them easier to transfer and a more desirable size for rooting.

Root initiation was $100 \%$ on the BM4 medium (data not shown). Roots appeared on the shoots after 7 days of culture, and after 4 weeks a healthy root system had fully developed. The rooted plants were easily acclimatized to a greenhouse environment and showed vigorous growth (Figure 1d). Other methods to induce root development were not attempted since this technique was so highly successful.

Micro-propagation methods for commercially important species of Asteraceae such as sunflower ( $\mathrm{Hel}$ ianthus annuus) employ a variety of techniques to regenerate plants (Alibert et al. 1994). There are also methods to micro-propagate other Asteraceae species of commercial value, such as feverfew (Tanacetum parthenium) (Simmons 1998), marigold (Tagetes erecta) (Vanegas et al. 2002), Echinacea pallida (Koroch et al. 2003) and safflower (Carthamus tinctorius) (Orlikowska and Dyer 1993). These techniques have increasingly been used on medicinally important Asteraceae species such as goldenrod (Solidago virgaurea, $S$. canadensis, S. gigantea and S. graminifolia) (Kelemba and Thiem 2004) and those which are rare, such as Saussurea obvallata (Joshi and Dhar 2003). In Canada, micro-propagation of the Gulf of St. Lawrence Aster, a rare species in Prince Edward Island, has been shown to have potential in conservation efforts (Stewart and Lacroix 2001).

Meristem culture has been extensively used for the clonal propagation of horticultural plants. Since the constituent cells of meristems are genetically stable, plants regenerated by in vitro culture of shoot apices without the callus-mediated process of organogenesis should result in the recovery of genetically identical progeny. Because the culture was started from a single seed and mass regenerated in tissue culture, genetic variability is limited. Sericocarpus rigidus propagates clonally in the wild by underground rhizomes, so in vitro mass clonal propagation could be a good strategy for preservation and reintroduction of this threatened species.

Our study is the first to show that the threatened Asteraceae species, $S$. rigidus, can also be successfully propagated using micro-propagation techniques. Only one germinated seed was available for use in the study. However, by its very nature, micro-propagation works at the level of single seeds or explants, so our situation is not atypical. The genetic variability of the Mt. Tzuhalem population of $S$. rigidus is not known, but since the plant occurs in clonal patches, it is unlikely that other seeds of $S$. rigidus would respond differently to micro-propagation. The best results for shoot mul-

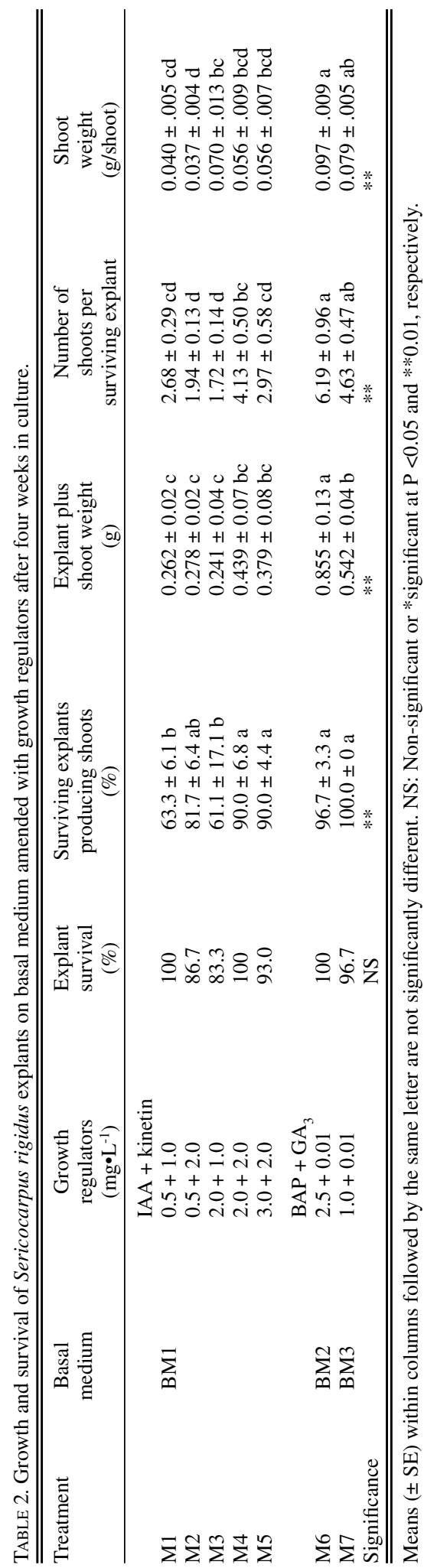


tiplication were obtained with combinations of BAP and $\mathrm{GA}_{3}$, a regime which has not often been used in other Asteraceae studies. Further work is required to determine the optimum basal medium formulation to use with the most successful combinations of BAP plus $\mathrm{GA}_{3}$ in order to generate the greatest number of vigorous $S$. rigidus shoots. Additionally, research with vegetative tissue as a source of explants, rather than seeds, could be conducted in order to avoid the time and difficulties associated with seed germination. However, from a conservation point of view, harvesting vegetative tissue, particularly rhizomes, from a threatened or endangered species may be less desirable than harvesting seeds because of damage to the plant and disturbance of the site.

The costs of micro-propagation were not evaluated against more conventional propagation techniques. Tissue culture is cost effective and is used commercially in the propagation of many plants. Although it requires more knowledge and extra capital to start a micropropagation operation, the rate of propagation is much faster than in conventional propagation. Given that hundreds of propagules of an endangered or threatened species may be generated using micro-propagation, the effort seems reasonable.

\section{Acknowledgments}

The authors thank Georgia Kliever and Frederic Bounaix for technical assistance, and Matt Fairbarns for collecting seed and providing advice. This study was partially funded by the Interdepartmental Recovery Fund of Environment Canada.

Documents Cited (marked * in text)

Environment Canada 2006. Species at Risk, White-top Aster. http://www.speciesatrisk.gc.ca/search/speciesDetails_e.c fm?SpeciesID=237.

Garry Oak Ecosystem Recovery Team. 2002. Recovery Strategy for Garry Oak and Associated Ecosystems and their Associated Species at Risk in Canada 2001 - 2006, 1 page.

\section{Literature Cited}

Alibert, G., C. Aslane-Chanabé, and M. Burrus. 1994. Sunflower tissue and cell cultures and their use in biotechnology. Plant Physiology and Biochemistry 32: 31-44.

Bigger, D. S. 1999. Consequences of patch size and isolation for a rare plant: pollen limitation and seed predation. Natural Areas Journal 19: 239-244.
Clampitt, C. A. 1987. Reproductive biology of Aster curtus (Asteraceae), a Pacific Northwest endemic. American Journal of Botany 74: 941-946.

Douglas, G. W., and J. M. Illingworth. 1997. Status of the white-top aster, Aster curtus (Asteraceae), in Canada. Canadian Field-Naturalist 111: 622-627.

Ehret, D., B. Frey, and T. Forge. 2004. Recovery of Endangered Species Inhabiting Garry Oak Ecosystems, PARC Technical Report (172), Agriculture and Agri-Food Canada, 12 pages.

Giblin, D. E. 1997. The relationships of reproductive biology and disturbance to the rarity of Aster curtus (Cronq.), a Pacific Northwest endemic. Master of Science dissertation, University of Washington.

Giblin, D. E., and C. W. Hamilton. 1999. The relationship of reproductive biology to the rarity of endemic Aster curtus (Asteraceae). Canadian Journal of Botany 77: 140-149.

Joshi, M., and U. Dhar. 2003. In vitro propagation of Saussurea obvallata (DC.) Edgew.- an endangered ethnoreligious medicinal herb of Himalaya. Plant Cell Reports 21: 933-939.

Kalemba, D., and B. Thiem. 2004. Constituents of the essential oils of four micropropagated Solidago species. Flavour and Fragrance Journal 19: 40-43.

Koroch, A. R., J. Kapteyn, H. R. Juliani, and J. E. Simon. 2003. In vitro regeneration of Echinacea pallida from leaf explants. In Vitro Cellular and Developmental Biology Plant 39: 415-418.

Kyte, L., and J. Kleyn. 1999. Plants from Test Tubes, an Introduction to Micropropagation. Timber Press Inc., Portland, Oregon.

Murashige, T., and F. Skoog. 1962. A revised medium for rapid growth and bioassays with tobacco tissue cultures. Physiologium Plantarum 15: 473-479.

Orlikowska, T. K., and W. E. Dyer. 1993. In vitro regeneration and multiplication of safflower (Carthamus tinctorius L.). Plant Science 93: 151-157.

Simmons, C. B. 1998. Pharmacognosy and micropropagation of feverfew (Tanacetum parthenium (L) Schultz Bip). Master of Science dissertation, University of Guelph.

Slater, A., N. W. Scott, and M. R. Fowler. 2003. Plant biotechnology: The genetic manipulation of plants. Oxford University Press, Oxford.

Stewart, S. E., and C. R. Lacroix. 2001. Germination potential, updated population surveys and floral, seed and seedling morphology of Symphyotrichum laurentianum, the Gulf of St. Lawrence Aster, in the Prince Edward Island National Park. Canadian Field-Naturalist 115: 287-295.

Vanegas, P. E., A. Cruz-Hernández, M. E. Valverde, and O. Paredes-López. 2002. Plant regeneration via organogenesis in marigold. Plant Cell Tissue and Organ Culture 69: 279-283.

Received 5 September 2006

Accepted 26 March 2007 